\title{
DERECHO A LA INTIMIDAD EN LAS REDES SOCIALES DE INTERNET EN COLOMBIA*
}

\author{
Ángela María Castro Jaramillo \\ Universidad Libre de Colombia - Seccional Cali
}

\section{Resumen}

El artículo ilustra uno de los temas más controversiales, en términos de lo jurídico y la comunicación, presentes en los inicios del siglo XXI: las redes sociales en Internet, que surgen como una respuesta a la naturaleza humana de comunicarse y de establecer vínculos personales, profesionales y sentimentales. Puesto que no existe una relación personal y directa con la persona con quien se está interactuando, puede haber lugar a vulneración de derechos fundamentales que se relacionan con el fuero interno de las personas. En el marco virtual de las redes sociales, es fácil proyectar un perfil que refleje una identidad que, en algunos casos, no corresponde a la realidad. El ambiente interactivo virtual se presta para que la persona que está al otro lado del computador suplante una identidad, como sucede con los individuos que solicitan amistad de personas con fines delictivos y ponen en riesgo la integridad y honra de las personas. La afectación del derecho a la intimidad desde las redes sociales es evidente, sea por terceros o por la misma persona titular que expone su vida privada sin medir las consecuencias y el impacto social, dada la rapidez de la difusión de la información que permite Internet.

Palabras clave: Internet, protección de los datos, redes sociales, tecnología de la información.

La autora: maestranda en Derecho Constitucional. Integrante del grupo de investigación en Derecho Administrativo, categoría C Colciencias. Correo electrónico: angelamaria.castrojarmillo@gmail.com

Recibido: 23 de noviembre de 2015; evaluado: 20 de enero de 2016; aceptado: 1 febrero de 2016.

Proyecto de investigación para optar el título de magíster en Derecho Constitucional de la Universidad Libre, seccional Cali. 


\title{
RIGHT TO PRIVACY ON ONLINE SOCIAL NETWORKS IN COLOMBIA
}

\author{
Ángela María Castro Jaramillo \\ Universidad Libre de Colombia - Seccional Cali
}

\begin{abstract}
The article examines one of the most controversial issues in terms of legal aspects and communication at the beginning of the 21st century: social networks on the Internet, which arose in response to the human need for communication and personal, professional, and sentimental ties. Since there is no direct personal relationship with the person you interact with, there might be room for the violation of fundamental rights related to the person's conscience. In virtual social networks, it is easy to project a profile that reflects an identity that, in some cases, does not correspond to reality. The virtual interactive environment allows for the person on the other side of the computer to change his or her identity, as it happens with individuals seeking friendship for criminal purposes, and to jeopardize the integrity and honor of individuals. The right to privacy is evidently affected by social networks, either by third parties or by the profile owners themselves who expose their private lives without considering the consequences and social impact, given the rapid dissemination of information allowed by the Internet.
\end{abstract}

Keywords: Internet, data protection, social networks, information technology.

About the author: Master's student in Constitutional Law. Member of the research group on administrative law, category C in Colciencias. Email: angelamaria.castrojarmillo@gmail.com

Received: November 23, 2015; reviewed: January 20, 2016; accepted: February 1, 2016. 


\section{Introducción}

Las redes sociales cambiaron la forma de interactuar entre los ciudadanos, pues propician espacios virtuales de mayor alcance y efectividad que satisfacen la necesidad de comunicarse e intercambiar información. Cada día, estas redes acogen mayor número de usuarios, las cuales permiten estar conectados y acceder a gran variedad de contenidos que exponen a los usuarios a situaciones que pueden vulnerar la intimidad personal e incluso familiar. Lo primero que se pretende ilustrar se desarrolla en el subtítulo "Surgimiento y expansión de las redes sociales en Internet desde lo sociojurídico"; se exponen el origen y el contexto en el que se desarrollan estas redes y se ofrece una idea más aproximada del por qué este fenómeno se ha desarrollado con tal rapidez en la actualidad.

En la segunda parte, "Límites y posibilidades del derecho a la intimidad en las redes sociales de Internet en el contexto colombiano", se delimitan los alcances que la Corte Constitucional y el desarrollo jurisprudencial han trazado para el manejo de casos donde exista una vulneración desde las redes sociales virtuales. En la última sección, "Consecuencias y alteraciones al derecho a la intimidad por los avances tecnológicos y las redes sociales", se presenta una idea del planteamiento general y cómo el derecho a la intimidad está cada día más expuesto, con el consentimiento del titular del derecho, sin medir las consecuencias que esto supone.

La importancia del tema radica en establecer cómo el derecho constitucional a la intimidad de los ciudadanos es vulnerado en las redes sociales de Internet, en el contexto colombiano. Cada día se vuelve más preocupante la exposición de la vida privada en las redes sociales y las implicaciones que esto conlleva.

Existe una tensión entre el derecho a la intimidad y la libertad de expresión, ambos lesionados a diario en Internet, dada la facilidad que los avances tecnológicos le han brindado al ser humano para publicar datos e imágenes personales, incluso sin autorización de sus titulares.

Se han hecho algunos avances normativos respecto a las leyes de protección de datos personales y delitos contemplados en la ley penal relacionados con la libertad individual como violación ilícita de comunicaciones, ofrecimiento, venta o compra de instrumento apto para interceptar la comunicación privada entre personas, divulgación y empleo de documentos reservados, acceso abusivo a un sistema informático, violación ilícita de comunicaciones o correspondencia de carácter 
oficial, utilización ilícita de equipos transmisores o receptores y hasta suplantación de identidad; sin embargo, aún falta por explorar en este campo, pues la ley presenta vacíos jurídicos. Su alcance sigue siendo muy limitado. En el caso de la ley de datos personales, al autorizar el ingreso a redes sociales como Facebook o Twitter y aceptar sus términos y condiciones, se está avalando la utilización de su información y la garantía de la protección de la misma es mínima, si se considera que las redes sociales se encuentran alojadas en servidores de la nube en Estados Unidos o en lugares desconocidos y se puede hacer un uso indebido o no autorizado.

\section{Surgimiento y expansión de las redes sociales en Internet desde lo sociojurídico}

Las tecnologías afectan la cotidianidad y la vida de los ciudadanos. Su uso inapropiado ha llevado -de manera voluntaria, consciente o no- a exponer aspectos de la vida que pueden considerarse como íntimos.

La aparición de Internet se remonta a los últimos años del siglo XX:

Internet se originó en un audaz plan ideado en la década de los sesenta por los guerreros tecnológicos del Servicio de Proyectos de Investigación Avanzada del Departamento de Defensa estadounidense (Advanced Research Projects Agency, el mítico DARPA), para evitar la toma o destrucción soviética de las comunicaciones estadounidenses en caso de guerra nuclear. En cierta medida, fue el equivalente electrónico de las tácticas maoístas de dispersión de las fuerzas de guerrilla en torno a un vasto territorio para oponerse al poder de un enemigo con versatilidad y conocimiento del terreno. El resultado fue una arquitectura de red que, como querían sus inventores, no podía ser controlada desde ningún centro, compuesta por miles de redes informáticas autónomas que tienen modos innumerables de conectarse, sorteando las barreras electrónicas. Arpanet, la red establecida por el Departamento de Defensa estadounidense, acabó convirtiéndose en la base de una red de comunicación global y horizontal de miles de redes (desde luego, limitada a una élite informática instruida de cerca de 20 millones de usuarios a mediados de la década de 1990, pero cuyo crecimiento es exponencial), de la que se han apropiado individuos y 
grupos de todo el mundo para toda clase de propósitos, bastante alejados de las preocupaciones de una guerra fría extinta. ${ }^{1}$

Se debe reconocer que esta herramienta es de utilidad y aporte en algunos aspectos sociales, económicos, políticos, académicos y culturales, ya que la aparición de las redes sociales en Internet ha permitido que las personas estén actualizadas y conectadas de forma directa y simultánea con las complejas realidades mundiales y que se acorten distancias entre millones de personas consideradas ciudadanos del mundo.

Rodríguez y Torres afirman:

En cada comunicación se encuentra la sociedad mundial implicada, independientemente de la temática concreta de la que se trate y de la distancia espacial entre los participantes. Se suponen posibilidades de comunicación y se utilizan medios simbólicamente generalizados que no se detienen ante las fronteras regionales: el dinero, el poder, el amor, la verdad, etc., no se dejan alterar por las barreras nacionales o regionales. ${ }^{2}$

Internet impulsó la interconexión mediante redes virtuales, situación que transformó la forma de comunicarse. Resultado de esto fue el surgimiento de relaciones y escenarios por medio de datos que se encuentran en la red. Entre esos datos se encuentra cierta información que es considerada como íntima y que, al estar distribuida en la red, pasan a una esfera pública, lo que afecta el derecho a la intimidad de sus titulares, en un complejo contexto de globalización.

Lo particular de este fenómeno es que las innovaciones tecnológicas siguen avanzando y la privacidad va disminuyendo en igual proporción. Por ejemplo, los teléfonos inteligentes que tienen redes satelitales poseen aplicaciones como GPS, que ubican con acierto a sus usuarios durante las veinticuatro horas del día, entre otros ejemplos que afectan el principio de libertad, en el entendido de que lo virtual trasciende a lo real, con lo que algunos ciudadanos o instituciones públicas o privadas logran tener el control y almacenar la información recopilada con fines lucrativos e incluso delictivos. Winocur indicaba:

Manuel Castells, La era de la información. Economía, sociedad y cultura. Vol. 1 (Ciudad de México: Siglo XXI, 2005), 32-33.

2 Darío Rodríguez y Javier Torres, Introducción a la teoría de la sociedad de Niklas Luhmann (Ciudad de México: Herder, 2008), 75. 
Más que decir que Internet tiende puentes con la vida del mundo "real", se trata de vínculos estratégicos, y lo que ocurre cotidianamente se convierte en muchos casos, en el material de los espacios virtuales de interacción. No es cierto, entonces, que lo virtual trascienda lo real de forma automática. Los espacios de interacción pueden estar configurados de distintas maneras, y pueden experimentarse también de formas variables, pero no pierden nunca, enteramente, toda referencia a las realidades offline. ${ }^{3}$

El fenómeno de la globalización, junto con el surgimiento de las nuevas tecnologías y la comunicación virtual, permitió que la información se consolidara y expandiera por muchos lugares del mundo. Con la aparición de las redes sociales se avanzó en cuanto a las relaciones interpersonales, lo que las hizo muy atractivas para los usuarios.

[...] afirmación que autores como Frank Webster (1995), intentan establecer la idea de la existencia de una corriente de pensamiento que se podría denominar Teorías de la sociedad de la información, u otros como Peppino Ortoleva, Majid Tehranian, Fausto Colombo, Antony Giddens, Umberto Eco, Mark Poster, Dominique Wolton y Manuel Castell que intentan estudiar en qué medida la apropiación social de la comunicación e información parece estar ligada al cambio social. ${ }^{4}$

Determinar el surgimiento de las redes sociales en el mundo y sus innovaciones es una pretensión compleja, debido a que no existe un consenso, por ejemplo, en determinar cuál fue la primera red social en Internet. El Observatorio Tecnológico del Gobierno de España, en su publicación de abril de 2012, hace una relación cronológica de las principales redes sociales que cambiaron la forma de comunicarnos y del manejo de la información por medio de las publicaciones propias y de terceros:

2000. Estalla la "Burbuja de Internet". En este año se llega a la cifra de setenta millones de ordenadores conectados a la Red.

2002. Se lanza el portal Friendster, que alcanza los tres millones de usuarios en sólo tres meses.

Rosalía Winocur, "Procesos de socialización y formas de sociabilidad de los jóvenes universitarios en la red", en El consumo cultural en América Latina, coord. Guillermo Sunkel (Bogotá: Convenio Andrés Bello), 505.

4 Gustavo Cardoso, Los medios de comunicación en la sociedad red. Filtros, escaparates y noticias (Barcelona: UOC ediciones, 2008), 40. 
2003. Nacen MySpace, LinkedIn y Facebook, aunque la fecha de esta última no está clara puesto que llevaba gestándose varios años. Creada por el conocido Mark Zuckerberg, Facebook se concibe inicialmente como plataforma para conectar a los estudiantes de la Universidad de Harvard. A partir de este momento nacen muchas otras redes sociales como Hi5 y Netlog, entre otras.

2004. Se lanzan Digg, como portal de noticias sociales; Bebo, con el acrónimo de "Blog Early, Blog Often"; y Orkut, gestionada por Google.

2005. YouTube comienza como servicio de alojamiento de videos, y MySpace se convierte en la red social más importante de Estados Unidos.

2006. Se inaugura la red social de microblogging Twitter. Google cuenta con 400 millones de búsquedas por día, y Facebook sigue recibiendo ofertas multimillonarias para comprar su empresa. En España se lanza Tuenti, una red social enfocada al público más joven. Este mismo año, también comienza su actividad Badoo.

2008. Facebook se convierte en la red social más utilizada del mundo con más de 200 millones de usuarios, adelantando a MySpace. Nace Tumblr como red social de microblogging para competir con Twitter.

2009. Facebook alcanza los 400 millones de miembros, y MySpace retrocede hasta los 57 millones. El éxito de Facebook es imparable.

2010. Google lanza Google Buzz, su propia red social integrada con Gmail; en su primera semana sus usuarios publicaron nueve millones de entradas. También se inaugura otra nueva red social, Pinterest. Los usuarios de Internet en este año se estiman en 1,97 billones, casi el 30 \% de la población mundial. Las cifras son asombrosas: Tumblr cuenta con dos millones de publicaciones al día; Facebook crece hasta los 550 millones de usuarios: Twitter computa diariamente 65 millones de tweets, mensajes o publicaciones de texto breve; LinkedIn llega a los 90 millones de usuarios profesionales, y YouTube recibe dos billones de visitas diarias.

2011. MySpace y Bebo se rediseñan para competir con Facebook y Twitter. LinkedIn se convierte en la segunda red social más popular en Estados Unidos con 33,9 millones de visitas al mes. En este año se lanza Google+, otra nueva apuesta de Google por las redes sociales. La recién creada Pinterest alcanza los diez millones de visitantes mensuales. Twitter multiplica sus cifras rápidamente y en sólo un año aumenta los tweets recibidos hasta los 33 billones. 
2012. Actualmente, Facebook ha superado los 800 millones de usuarios, Twitter cuenta con 200 millones, y Google+ registra 62 millones. La red española Tuenti alcanzó en febrero del año 2012, los 13 millones de usuarios. ${ }^{5}$

La red social mundial más reconocida ha sido Facebook, pues con la creación de un espacio de conversación virtual y la capacidad para conectar a los usuarios con su círculo familiar y personal atrajo a 1.100 millones de usuarios ${ }^{6}$ que permanecen interconectados las veinticuatro horas. Esto provoca en las personas una sensación de libertad, para que actúen con la mayor naturalidad y con tranquilidad, al punto de exponer a la luz pública aspectos que forman parte de su fuero privado e íntimo y dejan ver sus pensamientos en la vitrina de Internet, en particular, en la red social Facebook:

El ciberespacio realiza operaciones aparentemente contradictorias. Representa, por un lado, un crecimiento del espacio-público-en-general si consideramos que el espacio-público-real en la red de computadoras hace surgir, en su plena capacidad, el espacio-público-virtual. Aquí el ciberespacio tiene, potencialmente, la capacidad de crear comunidades transnacionales más diversas, ya que son necesariamente desterritorializadas o desgeograficadas. Son culturalmente más diversas a pesar de que: a) están ubicadas en un mismo medio, internet; b) se encuentran frecuentemente bajo el mismo paraguas simbólico, y lingüístico, a través, por ejemplo, de la utilización del inglés, o creole de la comunidad transnacional imaginada-virtual; y c) presentan una homogeneidad de origen de clase y raza. Por otro lado, el ciberespacio promueve un encogimiento del espacio-público-real, pues está íntimamente relacionado con la (re)producción del individualismo y de las formas de soledad de las sociedades contemporáneas. Las personas pueden usufructuar una sociabilidad virtual desde sus hogares protegidos de lo imprevisible y de los maleficios que pueden alcanzar los que transitan por espacios-públicos-reales, tendencialmente inseguros y deteriorados. A fin de cuentas, una de las "ventajas" del espacio-público-virtual es que puede ser narcisísticamente construido y controlado. ${ }^{7}$

Isabel Ponce, "Monográfico: Redes Sociales", http://recursostic.educacion.es/observatorio/web/es/internet/ web-20/1043-redes-sociales?showall=1 (acceso agosto 15, 2015).

6 Ana Nieto, "Las 30 redes sociales más utilizadas", http://www.webempresa20.com/blog/las-30-redes-socialesmas-utilizadas.html (acceso agosto 20, 2015).

7 Néstor García Canclini, Reabrir espacios públicos. Políticas culturales y ciudadanía (Ciudad de México: UAM, Plaza y Valdés, 2004), 94. 
El perfil de Facebook inicia con varias preguntas consecutivas, relacionadas con lo personal y lo íntimo del usuario: ¿Qué estás pensando? ¿Cómo está su estado de ánimo? ¿Quiénes son sus amistades? ¿Cuál es su situación sentimental? ¿Cuál es su actividad laboral? ¿Cuál es su actividad académica? ¿Cuál es su universidad? ¿Cuál es el lugar donde vive? Mas la red no se limita a estas preguntas, pues construye un historial con las actualizaciones del perfil, con lo que quedan consignados gustos y situaciones sentimentales, políticas y religiosas. ¿Cuántas relaciones de noviazgo y matrimonios ha tenido? ¿Cuántas culminadas? ¿Cuáles son sus ideas políticas? ¿Cuál es su religión? Al responder estas preguntas, se está dando a conocer públicamente asuntos propios de la privacidad, lo que en algunas situaciones puede afectar de forma negativa la integridad y el buen nombre de las personas. La información que aceptan divulgar se convierte en propiedad de estas redes, amparadas en la aceptación de sus términos y condiciones.

Analizado desde una perspectiva constitucional, el derecho a la intimidad en el contexto de las redes sociales es interesante. Es determinante delimitar los alcances y mecanismos jurídicos en caso de vulneración de este derecho fundamental, pues la sociedad actual necesita ser vista públicamente y la intimidad es cada día más limitada.

[...] en las últimas décadas la forma de construir la identidad cambió. En la sociedad del siglo XXI, la llamada sociedad del espectáculo, es cada vez más importante ser visto. Una persona existe en tanto la gente ve y sabe lo que hacen otros. Por ello, para muchos una parte de la vida en Internet, consiste en mantener al día su imagen en las redes sociales. Ahora se construye en torno de la imagen, el estilo, el performance. Si nadie nos ve, corremos el riesgo de no existir, otra vertiente de este aluvión son los diarios íntimos publicados en la web, para cuya confección se usan palabras escritas, fotografías, y videos. Son los famosos webblogs, fotologs y videologs, una serie de nuevos términos de uso tradicional cuyo origen etimológico remite a los diarios de abordo mantenidos por los navegantes de otrora. Es enorme la variedad de estilos y asuntos tratados en los blogs de hoy en día, aunque la mayoría sigue el modelo confesional del diario íntimo. O mejor dicho: diario extimo, según un juego de palabras que busca dar cuenta de las paradojas de esta novedad, que consiste en exponer la propia intimidad en las vitrinas globales de la red. ${ }^{8}$

\footnotetext{
8 Paula Silbilia, La intimidad como espectáculo (Ciudad de México: Fondo de Cultura Económica, 2008), 13.
} 


\section{Límites y posibilidades del derecho a la intimidad en las redes sociales de Internet en el contexto colombiano}

La Corte Constitucional se ha pronunciado de forma clara y continua sobre el derecho a la intimidad y el tratamiento que esta recibe. En materia del derecho a la intimidad y a la imposibilidad de renunciar de manera absoluta al mismo, la Sentencia T-414 de 1992 señaló:

Toda persona, por el hecho de serlo, es titular a priori de este derecho y el único legitimado para permitir la divulgación de datos concernientes a su vida. Su finalidad es la de asegurar la protección de intereses morales; su titular no puede renunciar total o definitivamente a la intimidad, pues dicho acto estaría viciado de nulidad absoluta. ${ }^{9}$

En la misma Sentencia expresa la finalidad de proteger el derecho a la intimidad:

[... la la finalidad con la que se protege la intimidad como una forma de asegurar la paz y la tranquilidad que exige el desarrollo físico, intelectual y moral de las personas, vale decir, como un derecho de la personalidad. Esta particular naturaleza suya determina que la intimidad sea también un derecho general, absoluto, extra patrimonial, inalienable e imprescriptible y que se pueda hacer valer erga omnes, tanto frente al Estado como a los particulares. En consecuencia, toda persona, por el hecho de serlo, es titular a priori de este derecho y el único legitimado para permitir la divulgación de datos concernientes a su vida privada. ${ }^{10}$

En la colisión del derecho a la intimidad con el derecho a la información, la Corte ha reconocido la prevalencia de la intimidad en ciertos casos concretos:

[... no vacila en reconocer que la prevalencia del derecho a la intimidad sobre el derecho a la información, es consecuencia necesaria de la consagración de la dignidad humana como principio fundamental y valor esencial, a la vez, del Estado social de Derecho en que se ha transformado el país, por virtud de lo dispuesto en el artículo primero de la Carta de 1991. ${ }^{11}$

\footnotetext{
Corte Constitucional, Sentencia T-414 de 16 de junio de 1992, M. P. Ciro Angarita Barón.

Corte Constitucional, Sentencia T-414.

Corte Constitucional, Sentencia T-414.
} 
De manera reiterada y consistente, la jurisprudencia constitucional ha establecido:

[...] que en el ordenamiento jurídico colombiano el principio de la autonomía de la voluntad privada puede ser limitado por causa del interés social o público y el respeto de los derechos fundamentales: La autonomía de la voluntad privada y, como consecuencia de ella, la libertad contractual gozan entonces de garantía constitucional. Sin embargo, como en múltiples providencias la Corte Constitucional lo ha señalado, aquellas libertades están sometidas a condiciones y límites que le son impuestos, también constitucionalmente, por las exigencias propias del Estado social, el interés público y por el respeto de los derechos fundamentales de otras personas. ${ }^{12}$

Los derechos fundamentales tienen un efecto de irradiación en todos los ámbitos del Derecho, incluso el Derecho Privado. Así lo ha destacado la Corte Constitucional:

Una de las consecuencias del papel que ocupan los derechos fundamentales dentro del constitucionalismo contemporáneo, concebidos como un "orden objetivo valorativo", es el denominado efecto de irradiación en todo el ordenamiento jurídico, de manera tal que "al derecho privado que hasta entonces determinaba en solitario la configuración de las relaciones jurídicas y la decisión de los conflictos jurídicos, se le sobrepone otro orden jurídico; éste tiene incluso primacía sobre él, si bien conste sólo en principios jurídicos, además de escasos, muy amplios y frecuentemente indeterminados". ${ }^{13}$

El fenómeno de la constitucionalización se hace evidente en los diversos campos del Derecho: "El efecto de irradiación implica igualmente que derechos fundamentales tienen también un efecto horizontal, es una constante en el constitucionalismo contemporáneo reconocer la eficacia de los derechos fundamentales en el tráfico jurídico privado". ${ }^{14}$ Para la Corte, la protección y garantía de los derechos fundamentales es esencial en las relaciones privadas.

En relación con el ámbito de cobertura y eficacia de protección de los derechos fundamentales en las relaciones privadas, la Corte ha expuesto:

12 Corte Constitucional, Sentencia SU-157 de 10 de marzo de 1999, M. P. Alejandro Martínez Caballero.

13 Corte Constitucional, Sentencia T-632 de 15 de agosto de 2007, M. P. Humberto Sierra Porto.

14 Corte Constitucional, Sentencia T-632. 
[... sería errado sostener que como el artículo 86 constitucional señala que la acción de tutela procede contra los particulares que prestan un servicio público, aquellos que con su conducta afecten de manera grave y directa el interés colectivo o en los supuestos de subordinación o de indefensión, la eficacia de los derechos fundamentales entre particulares queda limitada a esos eventos. Por el contrario, debido precisamente al lugar que ocupan los derechos fundamentales en el ordenamiento constitucional colombiano y a su efecto de irradiación se puede sostener que el influjo de éstos cobija todas las relaciones jurídicas particulares, las cuales se deben ajustar al 'orden objetivo de valores' establecido por la Carta política de 1991. Cosa distinta es que la acción de tutela, como mecanismo idóneo de protección de los derechos fundamentales en las relaciones entre particulares sólo proceda prima facie en los supuestos contemplados por el artículo 86 constitucional. ${ }^{15}$

Entre los derechos fundamentales que son afectados de forma repetitiva en el espacio de las redes sociales se encuentra el derecho a la intimidad, que está reconocido por la Constitución y que en lo posible debe protegerse ante los particulares y las mismas instituciones públicas. En la Constitución, este derecho está plasmado formalmente en el Artículo 15:

Todas las personas tienen derecho a su intimidad personal y familiar y a su buen nombre, y el Estado debe respetarlos y hacerlos respetar. De igual modo, tienen derecho a conocer, actualizar y rectificar las informaciones que se hayan recogido sobre ellas en bancos de datos y en archivos de entidades públicas y privadas. En la recolección, tratamiento y circulación de datos se respetarán la libertad y demás garantías consagradas en la Constitución. La correspondencia y demás formas de comunicación privada son inviolables. Sólo pueden ser interceptadas o registradas mediante orden judicial, en los casos y con las formalidades que establezca la ley. ${ }^{16}$

El derecho a la intimidad en las redes sociales se relaciona con el tratamiento de bases de datos personales, por ejemplo, cuando se manipula información íntima de las personas; sin embargo, en este proceso se afectan otros derechos como el libre desarrollo de la personalidad, por eso, es necesaria la intervención de las instituciones estatales para protegerlos y las bases de datos en las que se convierten

15 Corte Constitucional, Sentencia T-634 de 13 de septiembre de 2013, M. P. María Victoria Calle Correa.

16 Asamblea Nacional Constituyente, Constitución Política de 1991, Legis. Bogotá, artículo 15. 
las redes sociales deben ser supervisadas por ellas. Además, sería preciso que los directamente implicados pudieran participar en las decisiones de sus datos en Internet, que se encuentran almacenados en redes sociales como Facebook, Twitter, Instagram y WhatsApp, entre otras.

La Corte Constitucional ha establecido la vulneración del derecho a la intimidad en las redes sociales y determina las acciones que llevan a la afectación de este derecho:

Con relación a la posible afectación a los derechos fundamentales en redes sociales como Facebook, la Corte señaló en la sentencia T-260 de 2012: los derechos de los usuarios de esta red social pueden verse vulnerados con la publicación de contenidos e información en la plataforma -fotos, videos, mensajes, estados, comentarios a publicaciones de amigos- ${ }^{17}$

\section{Consecuencias y alteraciones al derecho a la intimidad por los avances tecnológicos y las redes sociales}

El concepto de intimidad se ha ido transformando debido a la facilidad que tienen las redes sociales para divulgar y difundir la información que era considerada privada y que, en la actualidad, los usuarios consideran posible que se publique. Con ello se asiste a la desfiguración de la intimidad como derecho fundamental y se permean los límites entre lo privado y lo público, deliberación a la cual no ha sido ajena la Corte Constitucional:

En este sentido, esta Corporación hizo mención a las potentes herramientas con que cuentan las redes sociales para el intercambio, procesamiento y análisis de la información facilitada por los usuarios, quienes en un primer momento pueden no prever el mayor alcance de estas herramientas. En este contexto, la Corte consideró que de manera concomitante al aumento de posibilidades para compartir, comunicar y entretener, las redes sociales generan también riesgos para los derechos fundamentales a la intimidad, protección de datos, honor, honra, imagen y buen nombre, entre otros. ${ }^{18}$

\footnotetext{
7 Corte Constitucional, Sentencia T-634.

18 Corte Constitucional, Sentencia T-634.
} 
Pese a que la intimidad como concepto ha variado por los medios de comunicación y las nuevas tecnologías, en ciertos casos concretos la Corte protege este derecho fundamental de los ciudadanos:

Reiteradamente esta Corporación ha señalado que el derecho a la intimidad permite y garantiza en los asociados, el poder contar con una esfera o espacio de vida privada no susceptible de la interferencia arbitraria de las demás personas, que al ser considerado un elemento esencial del ser, se concreta en el derecho a poder actuar libremente en la mencionada esfera o núcleo, en ejercicio de la libertad personal y familiar, sin más limitaciones que los derechos de los demás y el ordenamiento jurídico. En ese orden de ideas, y al no ser un espacio que forme parte del dominio público, obedece al estricto interés de la persona titular del derecho y por consiguiente no puede ser invadido por los demás. Por esta razón, ese espacio personal y ontológico, sólo "puede ser objeto de limitaciones" o de interferencias "en guarda de un verdadero interés general que responda a los presupuestos establecidos por el artículo lo. de la Constitución". La jurisprudencia de la Corte Constitucional tal y como se ha dicho, ha señalado que el derecho a la intimidad es entonces, inalienable, imprescriptible y solo susceptible de limitación por razones legítimas y debidamente justificadas constitucionalmente. ${ }^{19}$

Ante la expansión de las redes sociales virtuales y la masiva incorporación de ciudadanos a ellas, las interpretaciones constitucionales están al orden del día. Dada la posibilidad de exigibilidad judicial de derechos que son vulnerados de forma constante en Internet, estos derechos son protegidos por la acción de tutela y otras posibilidades constitucionales y jurídicas.

Los avances en las redes posibilitan la rapidez con la que se difunde la información por estos medios. Este fenómeno de interconectividad ha llevado a que la regulación jurídica aparezca paulatinamente, situación que conduce a formular inquietudes como ¿cuál derecho fundamental deberá prevalecer en el tratamiento de los datos personales referente al acceso a redes sociales? ¿Derecho a la intimidad, derecho a la información o derecho al buen nombre? ¿Qué instrumento jurídico utilizaría una persona cuando se vulnera su derecho a la intimidad en una red social de Internet, fuera del perímetro colombiano? Estos interrogantes se convierten en faros de la discusión planteada.

19 Corte Constitucional, Sentencia C-640 de 18 de agosto de 2010, M. P. Mauricio González Cuervo. 


\section{Derechos fundamentales: planteamientos teóricos}

Luigi Ferrajoli sostiene:

[...] los derechos fundamentales son todos aquellos derechos subjetivos que corresponden universalmente a todos los seres humanos; en cuanto dotados del status de personas, de ciudadanos o de personas con capacidad de obrar; entendiendo por derecho subjetivo cualquier expectativa positiva (de prestaciones) o negativa (de no sufrir lesiones) adscrita a un sujeto por una norma jurídica; por status la condición de un sujeto, prevista asimismo en una norma jurídica positiva, como presupuesto de su idoneidad para ser titular de situaciones jurídicas y/o autor de los actos que son ejercicio de éstas. ${ }^{20}$

Los derechos fundamentales tienen unas características fundamentales que los identifica y los ubica en una posición superior, frente a los otros veintiocho derechos contenidos en la Constitución. Así lo argumenta la teoría de Robert Alexy:

En el Estado democrático de Derecho -como el alemán-, los derechos fundamentales tienen cuatro características fundamentales: El máximo rango. La máxima fuerza jurídica. La máxima importancia del objeto. El máximo grado de indeterminación. El máximo rango es el resultado de la circunstancia de que los derechos fundamentales se hallan regulados por la constitución. De ahí que toda norma que los infrinja es inconstitucional y en consecuencia nula por regla general. La máxima fuerza jurídica hace referencia a que los derechos fundamentales no se limitan a ser meras declaraciones programáticas, sino que gozan de tutela judicial en todos los sentidos, las leyes solo en el marco de los derechos fundamentales. La máxima importancia del objeto indica que mediante los derechos fundamentales se decide acerca de la estructura básica de la sociedad y se definen los límites del Estado. El máximo grado de indeterminación significa que los derechos fundamentales son lo que son sobre todo a través de la interpretación. ${ }^{21}$

Asimismo, la teoría de los derechos fundamentales de Robert Alexy contiene un sistema combinado de principios y reglas de derecho fundamental, en el que las normas adquieren un carácter doble:

20 Luigi Ferrajoli, Los fundamentos de los derechos fundamentales (Madrid: Trotta, 2001), 19.

21 Robert Alexy, "Los derechos fundamentales en el Estado democrático de Derecho" en Neoconstitucionalismo(s), ed. Miguel Carbonell (Madrid: Trotta, 2003), 32-33. 
Por un lado, se define por los rasgos propios de los principios, en consonancia con la idea de argumentación correcta. Pero, por otro lado, sigue teniendo peso la validez jurídica de las normas que contienen derechos fundamentales, consideradas como reglas constitucionales. ${ }^{22}$

En cuanto al derecho a la intimidad como un derecho constitucional, se hace fundamental analizar también la teoría jurídica contemporánea de la ponderación, de Robert Alexy, como la técnica consistente en resolver los conflictos entre principios que establecen derechos fundamentales:

El hecho de que, a través de las disposiciones iusfundamentales, se estatuyan dos tipos de normas, es decir, las reglas y los principios, fundamenta el carácter doble de las disposiciones iusfundamentales, por lo pronto. Ellas son reglas (por lo general, incompletas) o principios. Pero se obtienen normas iusfundamentales de carácter doble si se construye la norma iusfundamental de forma tal que en ella los dos niveles estén ensamblados. Una vinculación tal de ambos niveles surge cuando en la formulación de la norma iusfundamental se incluye una cláusula restrictiva referida a principios y, por lo tanto, sujeta a ponderación. Por lo pronto, recurriendo al caso de la libertad del arte habrá de mostrarse cuál puede ser el aspecto de tales cláusulas ajenas a ponderación. ${ }^{23}$

En el mismo sentido, el doctor Carlos Bernal Pulido plantea dos formas básicas para aplicar normas: la ponderación y la subsunción.

Las reglas se aplican mediante la subsunción, al paso que la ponderación es la manera de aplicar los principios. Es por ello que la ponderación se ha convertido en un criterio metodológico indispensable para el ejercicio de la función jurisdiccional, especialmente la que se desarrolla en los Tribunales constitucionales, que se encargan de la aplicación de normas que, como los derechos fundamentales, tienen la estructura de principios. A pesar de ello, la ponderación se sitúa en el centro de muchas discusiones teóricas, que revelan que algunos aspectos tales como su estructura y sus límites, aún distan de estar del todo claros. La ponderación es la forma en que se aplican los principios jurídicos, es decir, las normas que tienen la estructura de mandatos de optimización. Estas normas no determinan exactamente lo que debe hacerse,

22 Robert Alexy, Teoría de los derechos fundamentales (Madrid: Centro de Estudios Constitucionales, 1993), 135-136.

23 Alexy, Teoría de los derechos fundamentales, 135-136. 
sino que ordenan que algo sea realizado en la mayor medida posible, dentro de las posibilidades jurídicas y reales existentes. Las posibilidades jurídicas están determinadas por los principios y reglas puestas, y las posibilidades reales se derivan de enunciados fácticos. Para establecer esa "mayor medida posible" en que debe realizarse un principio, es necesario confrontarlo con los principios opuestos o con los principios que respaldan a las reglas opuestas. ${ }^{24}$

Las fórmulas de la ponderación y la subsunción han facilitado un resultado más claro y preciso en lo que respecta a dirimir conflictos entre derechos fundamentales y, en algunos casos concretos, facilitan la resolución.

Existen dos tipos de amenazas contra la intimidad: la acción o intrusión en un espacio o zona propia, y el conocimiento o intromisión informativa sobre los hechos, datos o aspectos relativos a la vida privada de una persona. Puede hablarse, en consecuencia, de una intimidad "territorial" y de una intimidad "informacional", que también puede llamarse confidencialidad. ${ }^{25}$

Es necesario que exista un espacio íntimo en donde no intervengan ni el Estado ni particulares; un espacio en el que no solo tenga injerencia el titular del derecho a la intimidad y, como titular, sea este quien elija libremente sus prácticas sexuales y tendencias políticas, económicas, culturares que son de importancia para él y los suyos, es decir, su familia. Así se hace relevante marcar la diferencia, pues en otro caso estaríamos dejando expuestas áreas privadas que son cada día menos propias.

El derecho a la intimidad, se encuentra justificado en la necesidad de separar el ámbito de lo privado y lo público. Y puede hablarse de violación a la intimidad al menos en los siguientes casos: Cuando se genere una intrusión en la esfera o en los asuntos privados ajenos. Cuando se divulguen hechos embarazosos de carácter privado. Cuando se divulguen hechos que suscitan una falsa imagen para el interesado a los ojos de la opinión pública. Cuando se genere una apropiación indebida para provecho propio del nombre o de la imagen ajenos. Cuando se revelen comunicaciones confidenciales, como las que se pueden llevar a cabo entre esposos, entre un defendido y su abogado, entre un médico y su paciente o entre un creyente y un sacerdote. ${ }^{26}$

24 Carlos Bernal Pulido, "Estructura y límites de la ponderación", Doxa. Cuadernos de Filosofía del Derecho, núm. 26 (2003): 229.

25 Miguel Carbonell Sánchez, Los derechos fundamentales en México (Ciudad de México: UNAM, 2004), 2.

26 Carbonell Sánchez, Los derechos fundamentales en México, 450-455. 
El concepto de intimidad está ligado a la privacidad, a la esfera interna de las personas que, en la actualidad, parece estar cada día más expuesta al público.

Durante las últimas décadas y, en especial al final del siglo XX, debido a la influencia y al auge de la tecnología y de las telecomunicaciones, una manera de atentar contra este derecho a la tranquilidad individual está constituida por el asedio que los medios de comunicación realizan sobre las personas cuya vida pública es muy destacada. El objeto es lograr primicias o llevarle al público fotos, datos, o relatos de hechos íntimos que buscan satisfacer la curiosidad de un sector de los ciudadanos. ${ }^{27}$

Es evidente que la forma de comunicación cambió a raíz de los avances tecnológicos. El mundo se caracteriza por el consumo masivo de información y su amplia circulación sin restricciones.

En Colombia se protege la intimidad personal y familiar y el buen nombre y se obliga al Estado a respetarlo y hacerlo respetar. El poder público que ejerce el Estado mediante sus instituciones debe ser real y efectivo. Las nuevas tecnologías avanzan con mucha rapidez, mientras la regulación aún está en un proceso de adecuación para ajustarse a las realidades de un contexto global.

Esta concepción del pluralismo jurídico tiene una mayor cercanía con teorías del Derecho como el realismo jurídico, que priorizan la realidad social ante lo normativo, las reglas o los derechos, y configuran lo judicial más allá de la percepción del juez que se configura exclusivamente del Estado o los Estados: por fin, los realistas compartían un espíritu reformista del Derecho, tanto en lo que afecta a su contenido normativo, como en lo referente a los métodos de su aplicación. Una y otras reformas eran vistas por los realistas como pasos necesarios para una acomodación entre el Derecho y las demandas de justicia, adaptación a los nuevos tiempos, y seguridad jurídica de los legos [...]. Un punto de vista epistemológico común ha de conducir necesariamente a una serie de constataciones muy básicas también [...]. (1) La concepción del Derecho como un flujo, de un derecho móvil, y de la creación judicial del Derecho. (2) La concepción del Derecho como un medio para obtener ciertos fines sociales

27 John Daniel Gutiérrez Boada, Los límites entre la intimidad y la información (Bogotá: Universidad Externado, 2001), 38 . 
y no como un fin en sí mismo. (3) La concepción de la sociedad como un flujo, típicamente más rápido que el Derecho [... ${ }^{28}$

En la teoría del realismo jurídico se logra identificar que el derecho a la intimidad en las redes sociales frente a la eficacia normativa, la fuerza estatal y la probabilidad asociada con las decisiones judiciales aún está en desarrollo. La ausencia de regulación ha generado incertidumbre frente al tratamiento que este derecho recibe y a las posibilidades reales y efectivas que tiene un ciudadano para defenderlo.

\section{Conclusiones}

En el contexto colombiano, preocupa la exposición de la vida privada en las redes sociales virtuales y las consecuencias que esto conlleva, pues se camina sobre una línea muy delgada entre el derecho a la intimidad, la honra y la propia imagen y la libertad de expresión, derechos vulnerados a diario en Internet. Esto se debe a la facilidad que los avances tecnológicos ofrecen para la publicación de datos e imágenes personales, incluso sin autorización de sus titulares, con lo que se abusa de la intimidad personal y familiar.

Se han hecho algunos avances normativos respecto a las leyes de protección de datos personales y delitos contemplados en la ley penal; sin embargo, siguen siendo insuficientes y no se cuenta con las garantías necesarias para reparar integralmente los daños morales y económicos ocasionados. Entonces, es menester analizar desde una óptica constitucional la protección y los límites del derecho a la intimidad de los ciudadanos colombianos que acceden a las redes sociales en Internet, así como promover, desde el Congreso, un estatuto que reglamente el derecho a la intimidad en las redes sociales virtuales.

Las políticas relacionadas con términos y condiciones que proponen las redes sociales dejan en desventaja al usuario, pues a pesar de que este es el creador del contenido, transfiere el derecho de propiedad sobre la información que publica, por lo que las imágenes y los videos de su autoría ya no le pertenecen y el uso comercial o delictivo que otro pueda darles deja a la intimidad personal y familiar en manos de un tercero. Por esto, es necesario tener claridad acerca de los usos y las prácticas sanas que deben hacer los usuarios en estas redes y conocer cómo,

28 Jairo Vladimir Llano, "Teoría del Derecho y pluralismo jurídico", Criterio Jurídico 12, núm. 1 (2012): 195. 
desde la costumbre o los instrumentos jurídicos, han sorteado en otros países los casos en los que se ha vulnerado el derecho a la intimidad y analizar la eficacia de las acciones jurídicas en un entorno virtual llamado Internet.

\section{Referencias}

Alexy, Robert. "Los derechos fundamentales en el Estado democrático de Derecho" en Neoconstitucionalismo(s), editado por Miguel Carbonell, 31-48. Madrid: Trotta, 2003. Alexy, Robert. Teoría de los derechos fundamentales. Madrid: Centro de Estudios Constitucionales, 1993.

Bernal Pulido, Carlos. "Estructura y límites de la ponderación". Doxa. Cuadernos de Filosofía del Derecho, núm. 26 (2003): 225-238.

Carbonell Sánchez, Miguel. Los derechos fundamentales en México. Ciudad de México: UNAM, 2004.

Cardoso, Gustavo. Los medios de comunicación en la sociedad red. Filtros, escaparates y noticias. Barcelona: UOC ediciones, 2008.

Castells, Manuel. La era de la información. Economía, sociedad y cultura. Vol. 1. Ciudad de México: Siglo XXI, 2005.

Corte Constitucional. Sentencia C-640 de 18 de agosto de 2010. M. P. Mauricio González Cuervo.

Corte Constitucional. Sentencia SU-157 de 10 de marzo de 1999. M. P. Alejandro Martínez Caballero.

Corte Constitucional. Sentencia T-414 de 16 de junio de 1992. M. P. Ciro Angarita Barón.

Corte Constitucional. Sentencia T-632 de 15 de agosto de 2007. M. P. Humberto Sierra Porto.

Corte Constitucional. Sentencia T-634 de 13 de septiembre de 2013. M. P. María Victoria Calle Correa.

Ferrajoli, Luigi. Los fundamentos de los derechos fundamentales. Madrid: Trotta, 2001.

García Canclini, Néstor. Reabrir espacios públicos. Políticas culturales y ciudadanía. Ciudad de México: UAM, Plaza y Valdés, 2004.

Gutiérrez Boada, John Daniel. Los limites entre la intimidad y la información. Bogotá: Universidad Externado, 2001.

Llano, Jairo Vladimir. "Teoría del Derecho y pluralismo jurídico". Criterio Jurídico 12, núm. 1 (2012): 191-214.

Nieto, Ana. "Las 30 redes sociales más utilizadas". http://www.webempresa20.com/blog/ las-30-redes-sociales-mas-utilizadas.html (acceso agosto 20, 2015). 
Ponce, Isabel. "Monográfico: Redes Sociales". http://recursostic.educacion.es/observatorio/ web/es/internet/web-20/1043-redes-sociales?showall=1 (acceso agosto 15, 2015).

Rodríguez, Darío y Javier Torres. Introducción a la teoría de la sociedad de Niklas Luhmann. Ciudad de México: Herder, 2008.

Silbilia, Paula. La intimidad como espectáculo. Ciudad de México: Fondo de Cultura Económica, 2008.

Winocur, Rosalía. "Procesos de socialización y formas de sociabilidad de los jóvenes universitarios en la red", en El consumo cultural en América Latina, coordinado por Guillermo Sunkel, 504-532. Bogotá: Convenio Andrés Bello. 